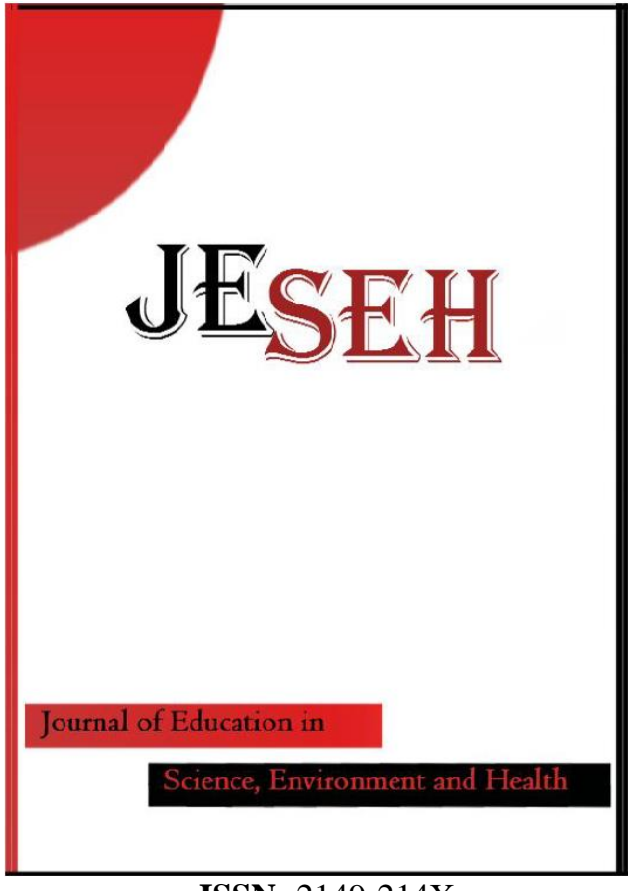

ISSN: $2149-214 \mathrm{X}$

\section{Journal of Education in Science, Environment and Health}

www.jeseh.net

Concept Teaching in Science Classrooms: A Critical Discourse Analysis of Teachers' Talk

Mensure Alkis Kucukaydin

Necmettin Erbakan University

To cite this article:

Alkis Kucukaydin, M. (2019). Concept teaching in science classrooms: A critical discourse analysis of teachers' talk. Journal of Education in Science, Environment and Health (JESEH), 5(2), 209-226.DOI:10.21891/jeseh.568813

This article may be used for research, teaching, and private study purposes.

Any substantial or systematic reproduction, redistribution, reselling, loan, sub-licensing, systematic supply, or distribution in any form to anyone is expressly forbidden.

Authors alone are responsible for the contents of their articles. The journal owns the copyright of the articles.

The publisher shall not be liable for any loss, actions, claims, proceedings, demand, or costs or damages whatsoever or howsoever caused arising directly or indirectly in connection with or arising out of the use of the research material. 


\title{
Concept Teaching in Science Classrooms: A Critical Discourse Analysis of Teachers' Talk
}

\author{
Mensure Alkis Kucukaydin
}

\begin{tabular}{|c|c|}
\hline Article Info & Abstract \\
\hline Article History & $\begin{array}{l}\text { Studies on science education stress that, in terms of discourse, teachers need to } \\
\text { carefully build their understanding of science, language, and authority to better }\end{array}$ \\
\hline $\begin{array}{l}\text { Received: } \\
07 \text { November } 2018\end{array}$ & $\begin{array}{l}\text { enable students to be successful in their science learning. However, the question } \\
\text { of how much attention should be paid to this discourse, particularly for primary }\end{array}$ \\
\hline $\begin{array}{l}\text { Accepted: } \\
22 \text { May } 2019\end{array}$ & $\begin{array}{l}\text { and middle-school students, remains controversial. This study examined the } \\
\text { discourse of two teachers, who teach science at the primary and middle- school } \\
\text { levels in different locations of Turkey, during concept teaching. The teachers }\end{array}$ \\
\hline $\begin{array}{l}\text { Keywords } \\
\text { Concept teaching } \\
\text { Critical discourse } \\
\text { analysis } \\
\text { Science teaching }\end{array}$ & $\begin{array}{l}\text { ideological structures related to social and pedagogical domains were analyzed } \\
\text { through critical discourse analysis. The results revealed certain differences } \\
\text { between the discourse of the teachers who teach at the primary and middle- } \\
\text { school levels. Several factors, such as the patriarchal structure of the society and } \\
\text { curriculum, lie at the bottom of these differences. }\end{array}$ \\
\hline
\end{tabular}

\section{Introduction}

In today's world, a great degree of emphasis is placed on science teaching, and the effectiveness of science teaching requires that teachers have a deep understanding of science concepts and their precise meanings. Many studies have indicated that students often stand aloof from science education due to their misunderstanding of scientific topics (Başer \& Çataloğlu, 2005; Layng, 2013; Tezcan \& Salmaz, 2005). In other words, one of the basic problems afflicting science education is students' lack of basic conceptual understanding regarding science. According to Tobias (1990), a vast majority of students do not like science because teachers tend to focus strictly on teaching facts, without showing any of the connections that exist between these facts, which results in them essentially overlooking big ideas. Furthermore, traditional applications and central exams are largely aimed at measuring how well students memorize the knowledge they possess, which leads to both primary and middle-school students being overwhelmed with unnecessary details, and the science lessons that furnish the students with the details are carried out in an uninteresting and non-inquiry based manner.

The same approach is mostly utilized in concept teaching, where each of the concepts is analyzed, and rational representations, which portray or do not portray the related concept, are made. In this way, a cluster of fragmented ideas ends up being created in students' minds (Layng, 2013). However, many of the schools and teachers that employ traditional approaches focus on a set of behavioral requirements for each course, introduce step-wise instructions to their students, and define concepts in an explicit way (Olson, 2008). Yet it is important that the students, rather than deal with only the details of concepts, examine the big ideas regarding the related concept and focus on the concept in this way. By doing this, teachers can better ensure that their students apply creative ways to understand concepts. This study aims to investigate the discourse used by teachers in concept teaching for science education in Turkey, and to determine the approaches they apply. In order to analyze the differences in discourse during concept teaching, an elementary school teacher and a science teacher, who teach science at different levels, were selected. One female teacher and one male teacher who teach at different locations were chosen, and their discourses were investigated at certain designated stages. However, the teachers' development within the process was not taken into consideration.

\section{Literature Review}

Concept Teaching in Science

Rosch (1999) defined concepts as the mechanisms individuals use to identify certain objects and asserted them to be open systems that students use to define new situations. von Glasersfeld (1995), on the other hand, characterized concepts as individual constructs to which mental images responsively yield via available 
perceptual cognitive material. Schill and Howell (2011) indicated that in science learning, particular attention should be attached to conceptual learning to enhance students' understanding, and they applied a "conceptual lens" approach to achieve this. With this approach, students examine their thoughts and express them in scientific ways.

For children, the learning and internalization of scientific concepts are viewed as a process. Freitas and Palmer (2016) mentioned that students can internalize this process by relating it to materials. Vygotsky (1987) investigated the concepts students use under two different categories: concepts they use in daily life and scientific concepts. This investigation was able to identify how scientific concepts are used and how the understanding of them can be improved in the early childhood period. With this information, Vygotsky intended to show and explain, using a dynamic methodology, that concepts are part of an extensive system. Dynamic methodology involves explaining the concept expression by conferring sense and thought onto objects. In essence, the concepts children use regarding daily life are obtained instinctively as a consequence of their immediate relation with the world. Green (1964) stated that education, in contrast to "teaching", can sometimes serve as an adequate tool for inculcating barbaric behavior. This is because teaching is an action that requires the expression of human behavior, and the discourse teachers use plays a decisive role in their teaching.

\section{Discourse Issues}

Discourse is a concept that can have various explanations, depending on the approach applied. While some researchers believe that discourse refers to all actions involving speech and writing, others consider it as actions involving speech network derivatives (Potter \& Wetherell, 1987). In different periods of time, humanity has worn different masks, and therefore, discourse differs by time periods (Parker, 1992). van Dijk (1997) discussed discourse according to daily-use language, arguing that it includes special and general speech-language, as well as the various shapes and forms they come in. Starting from the 1960s, discourse analysis, which began to be defined outside of its relationship with language, has become an interdisciplinary study domain. Within this new framework, discourse studies have involved different areas, such as text, speech, communicative action, film, and/or picture (van Dijk, 2007). Discourse analysis, which is included in the social structures required by recent educational approaches and is used to explain learning, has become an alternative theoretical perspective (Gee \& Green, 1998).

This diversity in the use of language led to the rise of different views regarding the analysis of discourse. Some scientists have put forward specific types and sub-branches or different methods -which are closely related approaches- of discourse analysis (Phillips \& Hardy, 2002). One of these methods was critical discourse analysis (CDA). The critical aspect of discourse analysis emerged in the 1970s, at which point discourse began to be defined on critical grounds. The work, Language and Control, written by Fowler, Kress, Hodge, and Trew (1979), was particularly pioneering, in terms of giving discourse studies a critical component. Critical discourse analysis is an approach that focuses on the investigation of the political and social contexts constituting discourse. In terms of their critical dimension, discourse studies introduce a rather broad conceptual and methodological framework, one that includes identity, awareness, and other elements (van Dijk, 2007). Discourse can be regarded as a structure that contains and systematically reproduces different power and authority relations. In terms of both structural and functional content, CDA is used as a method applied to investigate the relationship between authority, discourse, and action. This approach is regarded as a multidisciplinary analysis method that largely focuses on the language itself and the context wherein the language is used (Fairclough \& Wodak, 1997). Considering the functional and structural characteristics of the discourse together is among the priorities of CDA. CDA differs according to the discretion of the researcher performing the analysis, and concepts like discourse, criticism, ideology, and power are used with very distinct approaches. For this reason, CDA can be primarily regarded as a school of thought or as a program (Weiss \& Wodak, 2003). In the application of critical discourse analysis, the primary aim is to determine whether there is a need for a meta-theory for the interpretation of the meaning that constitutes the discourse or that is inferred from the discourse, and how to form the conceptual framework that is needed within the context of the content and the core of the problem (Weiss \& Wodak, 2003). Therefore, this study followed an interpretative perspective within the context of the content and research problem. In general, CDA attempts to understand the role of language, as a social tool, in terms of the social interactions within society, power dynamics, power distribution, institutions, and the formation and sharing of knowledge. In seeking to achieve this, CDA investigates how language mediates and provides a basis for determining power relations, benefits, and priorities (Gee, 1999). 


\section{Purpose}

The aim of this study is to investigate CDA of the primary school teacher and science teacher who teach in science classroom. For this purpose the following research questions have been addressed.

1. How are the primary school and middle school science teachers';

a) Discourse for in-class climate and cultivating a love of science,

b) Motivating discourse,

c) Discourse for the use of language in science classroom?

2. How is the primary school teacher and science teacher's discourse associating science with daily life and concept teaching in science classroom?

3. How is the primary school teacher and science teacher's towards students,

a) Discourse in gender issue,

b) Discourse in authority and power issue in science classroom?

\section{Method}

\section{Discourse Analysis}

Critical discourse analysis was used as the methodology in this study. Discourse analysis, a perspective that concerns social life, consists of methodological and conceptual elements and is characterized as a way of perceiving the discourse and transforming it into data. Discourse analysis is carried out independently of the general, theoretical, and quantitative approaches and it functions as a transition to detailed and qualitative approaches (Wood \& Kroger, 2000). In the last two decades, sociocultural theory-based discourse studies have grown to be more common in the effort to understand learning and teaching in social settings (Gee, 1999; Wertsch \& Toma, 1995). These studies involve analysis techniques that are developed by feeding off different disciplines and those feature restrictions based on the theoretical perspectives of these disciplines (Potter \& Wetherell, 1987; Tonkiss, 2004). According to Elliot (1996), criticism is at the center of discourse analysis, is used to reveal how social groups or individuals use language in order to attain power or to disseminate their ideological opinions. According to Kress (1990), CDA is a radically different type of linguistics, one that is based on certain assumptions.

"These assumptions include the ideas that language is a social phenomenon; that, not only individuals but also institutions and social groups, have specific meanings and values that are expressed in language in systematic ways; that texts are the relevant units of language in communication; that readers/hearers are not passive recipients in their relationship to texts; and finally, that there are similarities between the language of science and the language of institutions" (Wodak \& Meyer, 2001, p.6).

CDA achieves the objectives of investigation by revealing the social relations and identities existing in society on the basis of written and verbal texts (Luke, 1995). From this point of view, van Dijk (2003) explained the various purposes of discourse analysis as follows: In case studies, CDA should be better than all other marginal studies in order to be approved by all other marginal research methods. It should focus largely on social and political problems, rather than on existing paradigms and wordings. The critical analysis of the experimental competency of social problems should generally be conducted in a multidiscipline manner, and CDA should attempt to explain discourse structures on the basis of the social structure and the level of success in social interactions, rather than only describe and clarify discourse structures. CDA mainly focuses on the legalization, validation, legitimization, transformation, and restructuring of the power and authority relations in a society, or the challenging of them.CDA starts out by relating a social problem to the language in which it belongs to or other semiotic aspects. The actual analysis is initiated with the framing of the sociocultural applications within the text where this social problem is present. "This analysis of the social practice(s) surrounding the discourse practices under question includes identifying the relationship that exists between the discourse and other aspects of the social practice" (Hanrahan, 2005, p.14). Fairclough (2003) set forth three inter-related dimensions: a) text dimension, b) discursive practice dimension, and c) social practice dimension. The analysis of these dimensions is carried out in the form of linguistic and semiotic analysis and an inter discursive analysis, both of which are then related to each other (Hanrahan, 2005). According to Gee and Green (1998), discourse can never be objective, as they necessarily reflect a particular ideology, value system, or belief. Therefore, the entire text subject to the CDA should be analyzed at the micro, intermediate, and macro levels encompassing almost all social contexts. At the micro level, the teachers' word-related semantic, linguistic and phonological applications are analyzed, while at the intermediate and macro levels, the cultural, institutional, and textual structures generally governing the text are analyzed (Hanrahan, 2005). Despite being seemingly carried out in different 
contexts, the entire analysis is performed in an interrelated fashion, based on a specific philosophy. The main goal in CDA is to identify the ideological process presented in the discourse and to attempt to understand from the text the structural characteristics that the individual involved in this process possesses (Fairclough, 2003). That is to say, with the CDA, the discourse structure should be understood, considering that the CDA particularly looks for clues to how the ideological discourse is expressed in the text, the presence of any assumptions that may have been overlooked, and social structures. This is because teachers who are teaching in science classrooms will either consciously or unconsciously provide certain clues related to concept teaching.

\section{Participants}

In this discourse study, generalizations were derived from the data obtained from the discourse of two teachers who were teaching during the spring term of the 2017-2018 academic year in Turkey. David (pseudonym), one of the participants, is an elementary school teacher who has been teaching for 10 years in various public schools. David expressed his role as a teacher as follows: "I am a teacher who performs what my occupation requires. I consider myself competent in science teaching. The children show a great interest in experiments. I work with great devotion, using my experiences." He added that elementary school teachers in Turkey are reluctant to participate in the professional development training provided to them because they consider this training useless. He said that he actively uses various instructional materials (newspapers, microscopes, educational videos, and other sources to supplement the textbook) in the classroom environment. He believes that students can better learn science concepts by utilizing the trip-observation method and expressed that he performs most of his teaching in out-of-classroom environments. His school is located in a small village, where the classroom has a total of 10 third-grade students. Carla (pseudonym), the other participant, is a science teacher who has been teaching for six years in various public schools. Carla defined the role as a teacher as follows: "I am a teacher who innovative, closely follows scientific developments, can comfortably communicate with the students, and believes in discipline same time I consider love as the most essential component in education." Carla is a very active teacher and enthusiastically strives to fulfill the tasks assigned to her by the administrative board of the school. In her science teaching, she believes that she can learn something from her students. Carla works in a big school located in the city center and teaches science to students at middle school level. In this study, Carla's lessons with sixth graders were observed.

\section{Data Collection Process and Analysis}

After determining the purpose of the study, an elementary school teacher and a science teacher, who teach at different locations, were interviewed for the purpose of data triangulation. Other data sources are video recordings and all kinds of documents used by teachers in the course. After both teachers were informed about the purpose of the study and permission to conduct a video recording of their lessons was requested, they agreed to take part in the study. Video recordings were carried out for seven lesson hours for David and for five-lesson hours for Carla. Since the researcher was not able to be simultaneously present in the two classrooms at the same time, video recording devices were placed in the classrooms. The cameras were left on for two weeks, but the recordings obtained within this period were not taken into consideration, as the purpose behind leaving the cameras open was to familiarize both the teachers and the students with the presence of the camera in order make them comfortable expressing natural behaviors and discourse. Following the video recordings, an approximately 30-minute interview was conducted with the teachers. The interview included questions on the teachers' applications in the classroom and the justification of these applications.

The raw data obtained from the video records and the interviews were transcribed onto a form. This form included approximately 120 pages. The non-verbal data were then added to these data. As part of the first stage of the study, all the data obtained from the data collection tools were read several times, while the visual data and interview data obtained were analyzed using Jeffersonian system symbols* (Atkinson \& Heritage, 1984). Since the computer software, which can create images and transfer audio records into a written format, did not work for the Turkish language, the entire process was carried out manually. The transcription process took more than two months to complete. In order to facilitate the analysis process, the researcher applied different symbols which were unique to this study, in addition to the Jeffersonian system symbols. At the stage of microanalysis,

\footnotetext{
*Jeffersonian Transcription Notation includes the following symbols: Brackets, Equal Sign, Timed Pause, Micro pause, Period or Down Arrow, Question Mark or Up Arrow, Comma, Hyphen, Greater than / Less than symbols, Less than / Greater than symbols, Degree symbol, Capitalized text, Underlined text, Colon(s), High Dot, Parentheses, Double Parentheses. All of these symbols have a function in the text.
} 
the recordings were transcribed in written form and once again reviewed to confirm that the recordings and written transcription were in perfect correspondence. This was done in part to fulfill the purpose and targets of the study. Specifically, the microanalysis examined those paragraphs indicating the manner in which the teachers formed their respective in-class climate, how they cultivated a love for science in their students, and their motivating discourse. In the analysis of micro-level data, other themes, like misconceptions of the teachers, their understanding of the status quo, and curriculum emphasis, emerged. These sub-themes were described with examples. Since the focus of the study was the teachers' discourse, the students' conversations were not taken into consideration. However, no special effort was made to remove the students' conversations from the video recordings. Nonetheless, though the focus was strictly on the teachers' discourse, the fact that the students' conversation, as well as the physical and psychosocial characteristics of the environment, may have influenced the discourse of the teachers was clearly understood in this study. The entire text was analyzed based on the three-level CDA analysis process, as specified by Fairclough (1989). According to this, the first stage (the description stage) includes a comprehensive analysis of words, grammatical features, and assumptions - in other words; the vocabulary -where the focus is on the stress of lexical components and other metaphorical meanings. The second stage (the explanation stage) involves the analysis of ideological structure and practices in the social and pedagogical contexts. The last stage (the interpretation stage) involves the interpretation of both stages.

\section{Credibility}

In this study, CDA was applied to identify the structure of discourse used by David and Carla during concept teaching. Several techniques were used to secure the reliability of the study. As in all qualitative approaches, before using the visual images obtained from the teachers and the written form of the interviews, they were first presented to the teachers to get their interpretation and evaluation of the data. Following this stage, the opinions of two additional researchers, who were experts on the methodology of qualitative studies, were consulted about the suitability and comprehensiveness of the themes and the coding derived from the written forms. The fourthgeneration evaluation techniques proposed by Guba and Lincoln (1989) were used to confirm the reliability of the study. The first of these techniques involved long-term interactions with the participants. The researcher spent great lengths of time with David and the students in the classroom to help establish an environment of trust between him and the classroom, while in the case of Carla and her class, weekly meetings were performed, where the students identified the researcher as a teacher from a different school, to help establish this same sense of trust. These efforts at building trust in both classrooms provided a considerable advantage, in so far as they made the taking of audio recordings and field notes easier, which allowed for the research questions to be answered in a progressively simpler way.

\section{Results}

\section{The Primary School Teacher and Science Teacher's Discourse in Science Classroom}

David: David is an authoritarian teacher in his classroom. His students never intervene during his speech, and they pose their questions only after being allowed to by him. Physically, David is quite tall and strongly built. He always walks around the tables in the classroom and attempts to be in the driver's seat. When students are allowed to speak, they do so in a loud and clear voice, but other than that, there is hardly any noise in his classroom. The control of the classroom is completely under the authority of David, and activities are carried out based on the textbook. David constantly warns his students that they need to raise their hands if they wish to speak. For learning subject items that David deems important, he asks his students to repeat the related sentences, and he writes notes about these items on the board, telling his students to note them down in their notebooks at the end of the lesson. His speech is clearly understood in the classroom, and all of the students listen to him attentively. He generally talks in a loud manner in his classroom and distinctly enunciates his words. He also repeats loudly the answers to the questions he poses to his students.

Carla: Physically, Carla is average-sized, and she speaks quickly and loudly. In her speech, she repeats the words her students speak. On the issue of word choice, she focuses on technical words and avoids using daily language. However, she presents examples from daily life in order to facilitate understanding in her students. She is very sincere in her communication with her students. When she wants to clear the board, she asks "Is there a gentleman or a lady who would like to clear the board?"At hearing this, the entire classroom gets excited, and every student begs the teacher to choose them, saying "Please teacher, pick me". Her students can easily communicate with her, and female students, in particular, participate more in the lessons. She also presents options to the students in the questions she poses and uses encouraging words to advance the topic to 
be presented and in doing so, expects the students to master the topic. Carla does not tightly adhere to the curriculum or the textbook but rather, requires her students to question her ideas and produce new ones.

\section{Discourse for In-Class Climate and Cultivating a Love of Science}

In examining the structure of David's and Carla's discourse, it was found that both teachers used social experiences and daily events to teach science. The discourse identified in the observations was corroborated by the interviews conducted with the teachers. David, in his interview, indicated that he frequently uses laboratory practices in order to garner the students' attention and to cultivate a love of science in them, and that he felt this was the best way to accomplish these goals. However, during the seven-hour-long lesson observation conducted in David's classroom, he never did a single laboratory practice and only assigned homework about growing beans and grass. Besides having his students watch ready-to-use videos on the interactive whiteboard, David never went beyond the textbook. While these videos did strongly appeal to the students, there was no continuity to them due to the failure to engage in any conversation about the videos, as the teacher was the only one who spoke in the classroom. In the interviews, David described himself as a teacher who is responsible for presenting and explaining the science to the class. Yet, David had some misconceptions about teaching science-related concepts, and since he was not aware of this, these misconceptions were transmitted to his students. The concept, "work-oriented classroom approach" introduced by Hanrahan (2005, p. 33) holds true for David, as he expected all his students to carry out and complete the same task simultaneously. The students were obedient to the teacher, never made any inquiries, never talked without raising their hands, and expressed themselves using only a couple of words. Although the students were primary-school third-graders (age 9), they were quite silent in the classroom and did not pose any questions stemming from their curiosity. They sat for 40 minutes and were expected to perform the activities they were assigned. Therefore, David, as he stated in his interview, does not purport to raise future scientists.

Carla presented a quite idealist teacher profile in her interviews. The lesson observations also revealed that she puts forth efforts to nurture a love of science in her students and helps them to acquire a strong knowledge of science. However, Carla's classroom was considered poor in terms of sociocultural and academic achievement. She had just started her new position at her current school, and the school has a different institution culture from what she was accustomed to. Carla strived to break the sense of failure and frustration that dominated the climate of her classroom and the school. Carla, in her discourse, would sometimes get angry with her students when they failed to conduct research. In response, she would assign them homework to encourage them to make inquiries, even on extracurricular topics. In addition, Carla did feel of pressure from the curriculum. On this matter, she said "We need to complete our topics as quickly as possible, and I hope that the students can practice solving problems using different materials". In the interview, Carla said that she wanted to focus on in-class and out-of-class activities; however, she hurries through topics due to the intense curriculum applied. She further indicated that she pays close attention to her in-class discourse to cultivate a love of science in her students. On top of that, she places great emphasis on national values and expresses this in her lessons, asking her students to think critically about socio-scientific situations to further nurture a love of science in them. In addition, Carla's students participate in the lesson, attempt to engage in discussion, and do not hesitate to ask questions about topics they are curious about. Despite certain disadvantages related to the approach, Carla's classroom can be partially regarded as a "learning community-oriented classroom" (Hanrahan, 2005,p.33), as Carla provides opportunities for her students to make mistakes and responds to all questions her students ask out of a sense of curiosity. She presents new and interesting examples to them (Wall-E, automotive engineering etc.). In the context of "learning community", Carla looks to additional applications to meet her students' personal and social needs. In striving to nurture a love of science, she gives examples relevant to the environment of the students, in such a way that demonstrates the role of science in daily events. Furthermore, she encourages her students to speak in the lessons, even if they make mistakes, and attempts to make them use the concepts by including them in the discussions.

\section{Motivating Discourses}

David generally displayed the characteristics of the stylistic norms of school science proposed by Lemke (1990), with the exception that he spoke in a clear, concise and calm manner and helped to facilitate his students' acquisition of daily life related to the meaning of concepts. However, this style did not seem to be effective in the students' use of concepts, partly due to the tendency of David to use sarcasm in his discourse. The students talk in a brusque, unassertive manner, using incomplete sentences when they are responding to a question posed to them on a topic. David sometimes laughs or pretends not to have heard questions posed by his students. His 
motivating expressions are mostly limited to "Come on, man", a street type of language. Carla's case is quite the opposite. When she cannot hear something a student has said she makes them laugh by saying "Children, I am old; I cannot hear your voice" and then proceeds to answer the question without any hesitation. Criticizing the disciplinary practice of writing the names of students who were loud on the board, she mentioned that the students need to talk and had no problem with that so long as it stayed within the framework of respect. From the interviews, it was made clear that Carla believes that students, particularly females, should be encouraged to participate in the lesson by giving them opportunities to talk.

\section{Discourse for the Use of Language}

In his lessons, David primarily gave the name of the concept related to basic terms and phenomena and asked his students what came to their minds when they heard this concept. The students would either give no response or make an explanation consisting of only a few sentences. In such cases, David would explain the concepts himself, speaking distinctly but with few words. This use of language can be considered as assistive in helping the disadvantaged students in his classroom understand the concept. However, these disadvantaged students did not participate in the lesson or react at all. Therefore, the explanation of the concept by the teacher prevented the formation of a dialogue environment in the classroom. Moreover, since there was no dialogue in the classroom, the misconceptions that the teacher had were transmitted to the students directly. Hence, this empowered the authority of the teacher in the classroom and served as a barrier to personal decision-making, making mistakes or self-expression, which are all necessary for the student. The students took no initiatives and showed no enterprise as a result of this controlling approach. Carla, on the other hand, used motivating sentences to encourage the students' participation in the lesson, expressed her appreciation when her students participated, and encouraged them to ask questions, wonder and conduct research. She kindly made requests using humoristic language and asked her students to also use kind language in the classroom. She provided feedback to the students' discourse on the concepts and did not accept one-word answers. In the case of David, it was clear that his use of discourse reflects the message that science has strict boundaries that must be adhered to and not be questioned, and that there is a single explanation for science-related concepts. The language and discourse David used is based on the idea that a concept should be expressed openly to students in order for them to adequately understand this concept. Carla, on the other hand, believes that science has an indefinite domain and should be questioned, and that students need to engage in discussion. In concept teaching, Carla, rather than explaining a science-related concept or directly introducing it to the students, asked the students to construct the concept on their own. She paid no mind to the concepts presented in the textbook and even went so far as to not look at how the textbook defined the related term. Based on this, it can be asserted that she, in the language and discourse she uses, directs her students to counter-ideological ideas that go beyond the standard patterns (unorthodox to the school culture).

A descriptive portrait of the discourses used by the two teachers was created in the manner as shown above in the excerpts presented for each teacher. In the following section, a presentation of this portrait is carried out, along with a discussion. Based on the nature of CDA, these portraits are investigated in terms of social context and their ideologies, as they relate to pedagogical discourse. David's and Carla's discourse have different structures in terms of the social context and the ideologies to which they subscribe. There were differences between the teachers as regards creating the in-class climate, cultivating a love for science in the students, motivating discourse, and the use of language.

\section{The Primary School Teacher and Science Teacher's Discourse Associating Science with Daily Life and Concept Teaching in Science Classroom}

David: During concept teaching, he primarily writes the name of the concept on the board and questions his students about this concept. However, there is no environment of discussion in the classroom. David constantly repeats the name of the concept and asks the students what they think about the concept. Students ask questions about the concept, and David presents explanations to these questions. At times, he starts a sentence and asks his students to complete it (T: Yes, that is to say, reproduction is ... (Students say "increasing")). He uses almost no technical words. All the examples he is present in his lesson are from daily life and explains with spoken language. The data obtained in the interview conducted with David indicates that he is of the opinion that daily language is more suitable for learning science and that technical words have no meanings for some students. David tends to avoid talking in the form of written language; he inserts his personal judgments when he speaks; and he feels strongly that science can be learned through daily experiences. Investigating this situation from a linguistic perspective, it can be argued that teaching science in this way is not that impressive in terms of 
stimulating reactions from students. He uses textbooks only as a guide to carrying out the activities. He usually uses sentences in the present or future tense ("We do this now", "we will learn this", "we will apply" etc.). His conversation with his students is limited to a "triadic dialogue pattern" (Lemke, 1990). In other words, he only focuses on words during concept teaching and does not include other students in this operation. It is interesting that David's students do not, in any way, attempt to break this triadic dialogue template. Students speak either too little or not at all and raise their hands only to answer the questions David poses, and their answers to these questions never exceed a few words. David does not use any of the more recently developed applications in concept teaching activities, and he carries out the lesson in a monotonous manner. Furthermore, he does not present any review or important information at any point in the lesson to students who are new to his class. The topic of the day is consistently repeated at the beginning, middle, and end of the lesson. David presents all of the information in a ready-to-use manner, and since he has a small class, he supports individual studies. However, David applies a teacher-centered approach and often uses the question-answer technique. In all the seven lesson hours observed, outside of presenting a documentary or some other academic video on the interactive whiteboard occasionally, he generally directly taught the lessons himself. He uses the activities in the textbook but does not supplement them with other teaching methods, such as trips, observations, or experiments. When calling on his students or speaking to them as a class, he would alternately refer to them as "lady, master, my man", which are commonly used in the local language, or as "children", and "friends". He uses the term "assistant" to refer to the students who help him in his lessons. He occasionally talks with his students in street language. In adopting a status quo perspective in the classroom, he sometimes uses sarcastic expressions. In one lesson, where he wanted to demonstrate the relationship between the intensity of voice and the distance it travels from its source, he gave a book to one of his students and asked him to read it aloud. First, he asked the student to read the book aloud in the classroom and then told him to go to different places outside of the classroom (the school corridor, stairs at the gate of the school, and school garden) and continue reading aloud. In instructing the student to go out of the classroom, he told him "Come on, S2, go ahead, go, go" (@@@!!!). By doing this, he was demonstrating his authority (demanding that his students move in the way he wanted them to move), stressing the objective in an unquestioned manner, and reinforcing the status quo of the teacher-centered approach he applied in teaching science. Martin (1997, as cited in Hanrahan, 2005) termed this situation the "appraisal system", which means that the words and behaviors expressed to increase the status quo. This perspective that the teacher possesses was complied with by the target group, who demonstrated no conflicting behaviors and did not question the truth or challenge the teacher. According to Eggins (1994), this situation eventually leads to the person in power no longer needing to engage in a tour de force. On occasion, David would sometimes use impolite expressions. The excerpt below relates to a lesson David taught on the topic of "characteristics of living creatures", where the students said that the blue whale was the biggest animal in the world.

T: Is the cheetah regarded as the speediest animal in the world? Cheetah. Yes, of course, if our interactive whiteboard opens ((He tries to open the interactive whiteboard)). Is this opened? $\uparrow$ Yeah!! $\uparrow Y e s$. There were lions in the documentary we watched yesterday, weren't there? How were they hunting? They were hiding and immediately started to chase when their prey appeared, and they caught them straight away. Let's see how fast the fastest animal in the world is, let's watch.

S2: My teacher, isn't the blue whale the biggest animal in the world ((The classroom gets stirred up))

$\mathrm{T}$ : Yes, it is known as the weightiest animal in the world. What is its weight? Is there anyone who knows?

S1: 30 TONS

S3:40 TONS

S6:70 TONS

S10:80 TONS

S9:45 TONS

$\mathrm{S} 1: 300$ TONS

S7:1000 TONS

S8:500 TONS

$\mathrm{T}$ : Man, don't just throw numbers out there.

For the rest of the lesson, David presents a documentary on the fastest and the slowest animals in the world.

T: Yes, a cheetah can reach a speed of $120 \mathrm{~km}$ per hour $\uparrow$. That is to say, nearly as fast as the speed of a car ((He starts the documentary and the entire class watches)).

T: Ohhh, do you see it? So, a rabbit can reach the speed of $75 \mathrm{~km}$ per hour ((In the documentary, the speaker says, "This bird, which is second on the list, can reach the speed of $150 \mathrm{~km}$ per hour." The 
teacher whistles. And, here it is, the top of the list. The peregrine falcon is at the top of the list. This bird reaches a speed of $320 \mathrm{~km}$ per hour when it starts to dive. The teacher again whistles)).

In his effort to include students with special needs, David always shows them attention and keeps them in mind when giving examples for the subject being taught. The examples he shows sometimes arouse a laugh from the students and even from himself. Being fond of food, David often integrates something to do with eating into the examples he presents. When he wants to get the students' attention, he claps vigorously, and to create a relaxed atmosphere in the classroom, he walks around the room, rests a hand on the shoulder of a student, and jokes with them. When he gets the desired response from the students, he uses reinforcement, telling them "well done". Being tightly attached to the textbook, David, in one of his lessons, asked his students to grow beans and grass as homework. However, the students were not able to complete this homework assignment on time. It was determined, from the observations, that David has some misconceptions about certain science concepts.

\section{Example 1: Natural and artificial light sources}

When teaching the topic of natural and artificial light sources, David assumed cloud-to-ground and cloud-tocloud lightning to be the same in terms of their formation and expressed this to his students in this way. In addition, he used the idea of fire to teach the event of electrification in the formation of lightning.

T: Who built the lighthouse?

Ss: Humans.

T: That is to say, it does cast light on its own.

S1: Lighting

T:Yes, lighting, isn't it? (.) It is natural. All right, how does lightning form?

$\mathrm{S} 2$ : When clouds collide with each other, cloud-to-cloud lightning occurs. For this reason, lightning is also artificial.

T: Lightning, hmmm. Now, we said lightning is artificial, S1? What kind of a light source is lightning? Can humans produce cloud-to-cloud lightning or cloud-to-ground lightning?

Ss: Noooo...

T: NO, THEY CANNOT. What is cloud-to-cloud lightning or cloud-to-ground lightning? They are a natural light source. So, what happens is a fire appears on its own when two clouds collide with each other. And we call this cloud-to-cloud lightning or cloud-to-ground lightning $\uparrow$. And, they are examples of natural light sources $(2 \mathrm{~s})$. That is to say, children, natural light sources form on their own and occur in nature, completely without human intervention. All right, what are artificial light sources?

$\mathrm{T}$ : NO, it is its own light source. It comes with its own light. So, a meteor is a light source as well.

Later in the topic of natural and artificial light sources, David talked about meteors as a light source.

T: What do we call all of these things? We call them artificial light sources.

S3: My teacher, what do meteors do?

$\mathrm{T}$ : ((He is looking at a picture of a meteor in the textbook)) The one in your textbook?

S3: Yes, there it is; what is it?

T: Yes, this is a meteor. Actually, what was happening when we were watching the Ice Age movie? What was the meteor doing? It was approaching $\uparrow$ but how was it coming from space? It was coming by firing, wasn't it? Can humans place a lamp, a light, or a battery in meteors $\uparrow$ ?

Ss: No:::

In the following lesson, David opened a video on the interactive whiteboard that was related to the topic. He repeated what was said in the video and would sometimes pause the video to make additional explanations. On one occasion, he put forward the following explanations on the formation of night and day.

T: Why is the earth dark at night? ((He paused the video)). What is this? It is the result of the earth's rotation. The sun is stationary; the Earth rotates. As the Earth rotates, what happens to the part facing the sun?

Ss: Daylight.

T: Yes, daylight. The part which does not face the sun:::

Ss: Dark.

T: That is to say, when we say daytime, how does the light of the sun reach the Earth? Do the rays reach the Earth in a perpendicular manner? And, what do the sun's rays bring to the Earth? It brings 
light $\uparrow$. However, since the Earth rotates at a slow pace, we gradually move towards darkness; that is, from daytime to nighttime.

\section{Example 2: Sound and sound sources}

In one lesson, David discussed the sounds humans can hear and played the telephone game in the classroom. He pointed out that they cannot hear the footsteps of ants or flies. David associated this situation with the size of our ears.

T: For example, a fly comes and lands on the table; it moves on the table. Do you know in which direction it moves? (.)

S5: But, we do not hear their footsteps, my teacher.

T: We can hear the footstep of humans though. I wonder why? ((The students quietly think about this))

S1: Because they are small, and we are bigger than them.

T: Children, our ears do not hear all of the sounds in our environment; we cannot hear some sounds $\uparrow$. Normally, ants, birds, bats, and insects produce sound when they walk $\uparrow$, but the sound coming to our ears is not at a level we can perceive $\uparrow$. We cannot hear these sounds. However, when a human talks, a dog barks, a car makes a noise, or an earthmover is operating, we can easily hear these sounds. For example, sometimes cars come quietly, $\uparrow$ you cannot perceive them at all, and before you know it, it is just beside you; our ears are not adequate to perceive all sounds::: We cannot hear the sound of ants walking on the ground or the sound of bats; humans cannot hear the sounds of natural events or the sounds earthquakes make before occurring; however, dogs, since they can hear these sounds that humans cannot hear, react. What do dogs do? They bark (hhh). That is to say, they can hear the sounds we cannot hear. <If our ears were a little bigger>, we could hear more sounds; however, since our ears are always at the same level, we have difficulties to perceive certain sounds.

Later on in the lesson, David attempted to construct the relationship between the sound source and the distance; however, in doing this, he presented incorrect information about bats.

T: Some animals in nature, for example, bats, can hear the sounds that we cannot hear, right?

S6: Yes.

$\mathrm{T}$ : What is one of the characteristics of bats?

S3: They are blind.

T: Yes, what is one of the characteristics of bats? They are blind. All right, based on what then do they move?

Ss: Sound.

T: Yes, they move based on sound. Since their sense of hearing is so strong, what do they do? They move based on sound.

In the last lesson observed, David discussed how plants reproduce, where he talked about how new species can be obtained by planting seeds.

T: Children, reproduction means <increasing, rising>. This is a common characteristic of living creatures. <Reproduction is an event that humans or other living creatures carry out in order to survive $>$. What happens in the case of no reproduction? Species will disappear over time, and once this happens, we can no longer see them $\uparrow$. However, what is the common characteristic of living creatures? Reproduction. Humans reproduce, animals reproduce, plants reproduce, birds, fish, they all reproduce. However, there are some differences in the reproduction. Some living creatures reproduce by giving birth and some living creatures reproduce with eggs. ALL RIGHT, HOW DO PLANTS REPRODUCE?

S7: By planting.

T: Hmm, what do you plant in soil? We once again plant the seeds we obtain from trees or plants. When we plant them, we generate a new kind of tree or plant.

Carla: Having an enthusiastic personality, Carla is quite kind to her students and expects them to treat her equally as kind in their conversation and behavior.

T: Let me clear the board at once ((She clears the board and continues to talk in an exciting manner after turning to face them again)). The topic on temperature requires you to recall information from 
earlier grade levels, a bit from fifth grade and a bit from seventh grade. Temperature, hmm, is one of the topics which is not included in your textbook. However, there are questions on this subject on your test. I hope that you are solving questions from different publications outside of your textbooks $\uparrow$.

Ss: Yes.

S9: My teacher, hand me that book.

T: ((She turns her back to the board and faces the student)) YOU MEAN BY HANDING?

S9: Could you please hand me the book?

T: Anyway, here you go $\uparrow$.

Carla calls her students by their names or uses the word "you" to refer to them. When teaching a new topic or making a definition of a new concept, she clearly expresses the concept and poses many questions about it, like "What comes to your mind about this concept?" She uses the classroom board in an effective way. She waits for students' confirmation of understanding after she makes a definition or explanation.

T: (...) It spreads. Well, how would you come up with a common definition for solids, liquids and gases? (,) Consists of particles:::

S1: Consisting of particles, occupying space, hmmm having a particular volume.

T: If it occupies space, then volume means something which occupies space in the universe. >You don't have to repeat it $<$. All right, does gas have a mass? ((Students think quietly and start to whisper)) Does gas not have a mass? $\uparrow$

Ss: It has mass.

T: For example, let's take cars. Some cars use LPG tubes. You fill the tank up with liters of gas. That's right, isn't it?

Ss: Yes

T: Does the gas consist of particles? Does each particle have mass?

S2: It does.

$\mathrm{T}$ : Then, what do we call something that has mass and occupies space in the universe?

Ss: Matter.

T: Matter. Matter consists of particles, right?

Ss: Right.

Carla does not want her students to adhere to standardized patterns. The students were making noise in the class at the time between the end of the break and the teacher's arrival back to the class, and the classroom leader complained to the teacher about the students who were being noisy when the teacher came back. In order to discourage these students from being noisy and talking, the classroom leader wrote the names of those students who were being noisy on the board. However, Carla objected to this system, although other teachers apply it in other lessons.

$\mathrm{T}$ : (...) Is it understood? What happens to the temperature of a matter if you remove heat from that matter?

S6: It is going to decrease.

$\mathrm{T}$ : It is going to decrease. However, a while ago, our friend said that the sun comes to mind when you speak about heat. There was no sun last week; we could not see it, right? The sun light could not completely reach us because it was behind the clouds. Since it was not able to give heat to us, the temperature, as it is today, was 12 degrees :::

Ss: It was not.

T: It was not. It was below 10 or between 11 and 12 degrees. Now you understand why? $\uparrow$ In that case, since I have already provided you with the definition of matter (,) I now want to define heat and temperature. We are going to move a bit beyond the topic of heat and temperature; but, I want you to see. ((She moves to the board and just as she is about to start writing...) I WANT TO WARN YOU, DO NOT WRITE THE NAMES OF THOSE WHO TALKED ON THIS BOARD! ((She gets angry)). If you are going to talk, you will do so in any case (hhh). Let us write "heat" here in big font ((She writes on the board)) and here let's write "temperature".

Carla includes national values in her discourse. Even though it is not related to the topic of the lesson, she talks about these issues with her students and assigns homework involving topics outside of the scientific context.

T:Children, actually, these topics are a bit easy for you (.) hmmm, or should I say, they are not that intense for you. We have learned about matter and heat; that is, how matter transmits heat to other matter? We are going to see how heat transmission occurs... Let us see what happens in heat isolation. 
What type of matter are we going to use in heat isolation? ((She moves towards the tables)). Let me fill in the classroom book ((She writes the objectives of the day in the book. She looks at the date)). What day is it today?

Ss: Monday

$\mathrm{T}$ : What date is it?

S7: The 12th

$\mathrm{T}$ : Does it have a special meaning?

S9: Yes. It is the 97th anniversary of the National Anthem ((The student is a bit uncertain))

T: Is it not The Acceptance of the National Anthem? All right, what is special about March 18 ? ((Whispers in the classroom, a period of waiting for two minutes)). Yes, tell me $\uparrow$ so I can learn it from you, maybe I do not know ((Again, she looks in the classroom book and checks the names)) Why is S11 always absent from school? ((She counts the names of everyone one by one and then raises her head from the book)). Yes, tell me what is the importance of March 18? ((Whispers once again start in the classroom))

S9: Civil defense

T: That was last week (.) What comes to your mind when I say Çanakkale?

S3: A place

T: Yes, Çanakkale is a place. However, what is its importance to us?

S8: War

S10: Martyr

$\mathrm{T}$ : Ohh, you have totally forgotten about the issue. $\uparrow$

S11: My teacher, by the way, happy belated International Women's Day.

T: Altogether@@. Thank you. Yes, when we say Çanakkale, why is it important to us? That is all? ((She gets angry)) I am giving you some nice homework, but it is outside the scope of our course. It is going to be on the Çanakkale Victory. Okay? = Look at how the war was fought on that front, what happened, how many martyrs do we have? Okay? And I want it tomorrow. That's your homework today. Did everybody write that down? ((She walks around the classroom)).

Eggins (1994) referred to the ratio of the number of words used to the total number of words as "lexical density". Based on this definition, Carla has a high lexical density. She frequently has recourse to saying "Is it correct?, Is it done?, Is it ok?, Is it understood?, Are there any problems?, and Let's do it". Even though she speaks loudly, students sometimes do not understand what Carla is saying. She speaks too fast and frequently repeats her sentences. In order to check if something is understood, she expects the students to complete her sentences.

T: Okay, wood is short-lived. All right, shall we do it this way? Let us do a couple of examples. Which is a heat conductor, which is a heat insulator? You tell me. Copper coffee pot?

S9: Well, hmm.

$\mathrm{T}$ : If we say once again well::: $\uparrow$

S8: ((He warns his friend)) Say its name completely.

T: Copper coffee pot?

Ss: Conductor.

T: Copper is METAL. Conductor. Styrofoam?

In addition, she tries to encourage her students who feel apprehensive about giving an incorrect answer.

S1: Insulator.

$\mathrm{T}$ : Insulator. Steel cooker?^

S5: Conductor.

T: Silicon wool? $\uparrow$

Ss: Hmm.(There are whispers))

T: Loudly::: Children I am old, I cannot hear your voice ((Chuckles start in the classroom)) Yes, S8?

S8: Insulator.

T: Insulator. Glass?

Carla believes that female and male students have different knowledge structures and is also of the opinion that different occupations attract their attention.

$\mathrm{T}$ : (...) Lignite and coal are said to be obtained by powdering and subsequent application pressure. What do we call liquid fuels? We mentioned gas oil. 


\begin{abstract}
Ss: Petrol
$\mathrm{T}$ : All right, what if we do not consider it as petrol, but within petrol...

S9: Benzine, diesel fuel.

T: What if we create categories of diesel fuel, benzine, and fuel oil. Gentlemen know that there are some cars that operate with benzine, and some with diesel fuel. Is that correct? $\uparrow$ What is the difference between them? Gentlemen? For example, tractors mostly use diesel oil. See, we say diesel fuel, diesel, right? ((There is silence in the classroom)) Do you know the difference between them? Gentlemen?^Have you ever noticed? What is benzine? That is to say, why benzine, why diesel fuel? Why do we say diesel fuel and diesel? (2s) Homework $\uparrow$ For the entire classroom. You investigate benzine, diesel fuel, and fuel oil, all of which are derivatives of petrol. What is <the difference> between them?

S12: Are we going to investigate all of them?

$\mathrm{T}$ : These three (2s). Gas oil is used in gas lamps and gas heaters ((She writes on the board)). Benzine is used in motor vehicles. I am going to write them in the most generalized form ((She points out)) These three for investigation (...) Among you, is there anyone who wants to be an automotive engineer?

S8: What teacher? ((The ones who heard of it for the first time))

$\mathrm{T}$ : Automotive engineer (.) Petrol engineer (4s). Machine engineer (2s). All right, new homework ((Chuckles start in the classroom)). You are also going to investigate automotive engineering, mechanical engineering and petrol engineering. Yeah, learn the occupations $\uparrow$ Teacher, doctor, soldier, these are not the only occupations (...)Gentlemen, or ladies, have you ever heard of these occupations $\uparrow ?(\ldots)$ What you want to be, your dreams, should appear in your minds. For example, S1 ((She points out the student)) can be a great automotive engineer.
\end{abstract}

Finally, Carla includes socioscientific-based discussions in her lessons to ensure that the students have a solid grasp of the topic. In relating these discussions to the topic of fuels, she mentions the importance of dams to the country, the use of natural fuels, and the consumption of water sources. She initiates a discussion based on the basic energy sources.

$\mathrm{T}$ : (...) The answer is natural gas. Among these fuel types, natural gas is the one which damages the environment the least. All right, where do we get the natural gas from? (.) ((No response from the students)) Haven't you watched the news? Let me ask from which country do we get it?

S12: Russia

$\mathrm{T}$ : We get it from Russia. This has become general knowledge. Children, in terms of natural gas $\uparrow$ well, we have mentioned the chemistry industry $\uparrow$ we are de-pen-dent on Russia. On this topic, is it understood? And, people opt to use natural gas in newly constructed places, new dwelling units. One of the reasons, maybe the biggest one, is that among the other fuel types, natural gas minimizes environmental pollution. All right, I will ask another question (7s). We are 1-2-3-4-15 people here. You all are the energy minister of this country. Your country gets so polluted that there is no clean air (.) anymore. Did you watch the movie Wall-E? A robot that is on its own in the world.

S9-S2: I did watch it. It was rather beautiful.

Ss: I have not heard of it.

S9: Wall-E?? What?

T: I am saying this for the ones who have not watched it yet. Wall-E is all alone in the world. There is not a single living creature. Wall-E is a robot. There is no single source of oxygen. The air is completely polluted. Carbon dioxide etc., and, the reason Wall-E can survive is that it does not breathe because it is a robot. Imagine that we are going to such a country, a world. And you are the person who is responsible for the energy in this world (3s). In order to minimize this air pollution in the world, you need to take precautions, particularly in terms of energy. Which types of energy would you use?

\title{
The Primary School Teacher and Science Teachers' Discourse toward Students
}

\section{Discourse in Gender Issue}

In this study, where critical analysis of the discourse of two teachers was carried out, the issue of gender had an effective impact onto the discourse. Hanrahan (2005) highlighted that an interaction exists between the gender of the teacher, the student and the researcher, and that these issues should be dealt with separately. To account for this interaction, one female teacher and one male teacher were intentionally selected for this study on concept teaching in science classrooms. The teachers selected participated in the study on a voluntary basis, and both teachers met with the author of this study prior to its start. It was important that the teachers had been 
working at their respective schools for a certain duration of time, and particular attention was paid to this situation because text analysis involves some limitations, as indicated by Fairclough (2003, p. 15), who defined these limitations as "involvement of texts in meaning-making, the causal effects of texts, and the specific ideological effects of texts." In order to overcome this limitation of studies, he proposed the analysis be performed within an ethnographic framework. With this purpose in mind, the study was based on the culture of the institution studied. However, Carla had started her new position at a different school (the school where this study was carried out), and therefore frequent visits were made to this school by the researcher, who attended one lesson per week, each in a different classroom, free of charge. The purpose behind this was to get familiar with the culture of Carla's school and to minimize the limitations associated with CDA. Both teachers were aware that the observation and interview records obtained from them were going to serve scientific purposes. Another reason Carla was included in this study was the low number of female teachers in the available sample population. There were not many female science teachers in the region where the researcher was located, and most of the teachers who were volunteers were teaching for particular hours in lessons at a particular fee (Turkey makes use of substitute teachers). This situation threatened the ability to observe their lessons, considering that their continuity in lessons was not always possible and they could be assigned to a different school.

The fact that David was a male teacher had no impact on the mixed gender structure of the classroom. That is to say, David tried to treat the male and female students in his classroom equally. However, in some cases, David did seem to have a bias in favor of male students, particularly in his in-class applications or in his tactile warning to students (he would touch them on the shoulder), where he would choose the male students. David did not make a distinction between his female and male students in his discourse but did so in his behaviors. In the interview, David expressed that he behaves in this way in order to prevent misunderstandings. On the other hand, there was no difference in the female and male students' approach to David. In his discourse, David used more sarcasm towards his male students, which can be attributed to David's patriarchal understanding. He was aware that his female students could possibly get offended by his sarcastic behaviors, as his students were rather shy. While David would call male students "mate" or "my man", which are cultural expressions, he would call the female students "lady". In short, David used different discourse for male and female students.

Carla has a teacher profile that is energetic and active, but she is not firm in her teaching approach and talks fast. Her personal teaching style contributed to her communication with her female students, as she did not allow them to talk with each other and was able to successfully keep their attention focused on the lesson. In her classroom, the female students, under the motivating discourse used by Carla, were willing to talk more. However, Carla, like David, included gender discrimination in her discourse, particularly when it came to talking about occupations. She stated that industries like the machine and automotive are more suitable for male students. Yet, in doing this, she was actually attempting to engage the attention of her male students, who seemed less attentive in the lesson. In other examples though, she included images of femininity and motherhood. For instance, at one time, she presented an example of pudding that mothers cook, and in the heat isolation topic, she said that men sometimes were lightly clad in cold weather. Carla's classroom was more dynamic than David's and not boring. However, Carla would sometimes get frustrated, as she expected more from her students, and the motivating sentences she used to encourage the students led to the sense of shyness and chuckles among the female students, which gave the impression that Carla was more interested in attracting only the female students' attention. However, this tendency cannot be regarded independent of the sociocultural context, as female students in the Turkish society always feel closer to female teachers. As a researcher, it is important to point out that the discourse of both teachers, including their gender-related discourse, was presented in an objective manner, along with their justifications. These justifications were obtained based on the teachers' approach to their students and the behaviors observed among their students.

\section{Discourse in Authority and Power Issue}

In David's classroom, the teacher was the main source of authority and decided on the activities to be carried out in the classroom, the topics to be completed and how to proceed with and shape the curriculum. David controlled the questions posted, and his students made explanations consisting of only a couple of sentences; in other words, an atmosphere of discussion was not formed at all. The ideas were not questioned, and only temporary answers were provided for the questions the students were curious about. This strict approach to teaching science is a barrier to building enterprising skills in the students and having them take initiatives. The students, as a result of this type of concept teaching, believed that science should not be questioned and that it can be learned through the knowledge transmitted by the teacher. Science taught in this way was limited to what the teacher said and the knowledge presented in the textbook. A single explanation regarding any given concept 
was given, and ready-to-use knowledge was presented to the students, as the teacher provided the definitions of scientific concepts. The impression received from the class observation of David is that his students avoid questioning authority for fear of being the laughing stock of the classroom; based on this, the teacher did not put that much effort into actually teaching. These observations were strongly related to the wording norms stated in the book by Lemke (1990) and indicated the powerful position of the teacher in the classroom. The main indicator of this position is the central place David holds as the expert of the classroom. To nurture a love of science in the students, David did little more than have his students watch videos; he did not use laboratory practices, did not question the argument structure of his students and stationed himself as the center of power in the classroom by adopting a teacher-centered approach.

Carla's case was different. She, rather than being the authority and center of power in the classroom, adopted the role of moderator in the classroom. She put forth efforts to encourage her students to engage in discussion and sought to identify their argument structures. She recommended extracurricular activities and applications. She did not include laboratory practices in the classroom, but this could be attributed to the inadequate facilities her school provides. Carla did not present the meaning of the concepts to her students; on the contrary, they constructed the meaning of the concepts together. She discouraged her students from forming incomplete sentences and attempted to relate science to the students' daily lives. Furthermore, she attempted to tacitly or directly encourage her students and did not shy away from being laughed at; rather, the teacher discourse was entertaining to the students and served to arouse discussion among the students. Nevertheless, Carla did not participate in the students' conversation related to extracurricular topics, as this was her way of protecting her dominance over the classroom. Rather than positioning herself as an expert in the classroom, she guided her students to facilitate their self-learning. She was able to successfully make learning more attractive by applying sociocultural examples. All in all, Carla's discourse was appreciative and supportive.

\section{Discussion}

A critical analysis of two teachers' use of discourse during concept teaching in elementary school and middle school science courses in Turkey was carried out in this study. According to the CDA performed, there were some distinct differences between the discourse used by the two teachers. These differences could have resulted from the teaching level or the gender of the teacher, either of which can be regarded as a reflection of the ideological perspectives the teacher possesses. The differences in the discourse used by the teachers were reflected on the behaviors of the students in their classrooms, limited the in-class student-teacher interactions, were effective on the classroom's center of power, and were determinative in nurturing a love of science in the students. That is to say, the teachers' discourse played a decisive role in the students' learning of science. In the study, the discourse of the male participant, who teaches at the elementary school level, indicated that certain cultural influences had an effect on his discourse, considering that he used discourse pertaining to his culture and used the patriarchal language inherent in the patriarchal society. Delpit (1995) and Calabrese, Barton, and Yang (2000) highlighted the cultural power of science and the cultural power of language, stressing the power of the language teachers use, how this power is obtained, and how the power culture of science is formed. In order to realize strong, effective science teaching, it is important that teachers improve their discourse and understand how this power culture has been formed. Moore (2008) argued that teachers are responsible for facilitating their students' use of scientific language and their understanding of this language, stressing that teachers who intend to establish the connection between scientific language and daily language need to advance this responsibility further. Calabrese, Barton, and Yang (2000) put forward that teachers must carefully construct their understanding of science, language, and authority in order for students to be successful in science learning. The female participant, Carla, who teaches at the middle school level, used powerful language to distinguish between the occupational preferences of her female and male students. Both of the participants' discourse point to a social reality, one that is reflected in their discourse at the expense of attracting students' attention. However, the patriarchal discourse of the female participant was not as disturbing as the one used by the male participant, considering that the former's use of it did not necessarily infer that she ideologically holds this perspective, but rather, that she had recourse to it to attract the students' attention and get them to engage in discussion. At this point, it is important to consider the differences in the curriculum at the different teaching levels. In this matter, the CDA can be used to compare the access to science that students who are taught by different teachers have. In fact, through the observations of the lesson, it was revealed that Carla experienced difficulties in completing the curriculum applied, and that she felt her students needed to know everything and take a test-oriented approach to study in order to prepare for the state-administered exams. To summarize, as part of the CDA, the teachers underwent long-term observation by the researcher, and the analyses were conducted over a sufficient time period for the purpose of presenting future policy recommendations. The results of these analyses showed that different applications for concept teaching in science lead to different 
styles of learning. At the level of elementary school, the concepts were presented in a clear and ready-to-use manner but the more entertaining and inquiry-based features of science were ignored. At the level of middle school, on the other hand, the explanations regarding the concepts were constructed together with the students, and scientific inquiries were carried out. However, the intense curriculum of science at this level put pressure on the teacher, which, coupled with the disadvantageous conditions, turned the science teaching process into preparation for the exam.

\section{Conclusion and Implications}

This study investigated the discourse of two teachers in Turkey using CDA and attempted to reveal how concept teaching is performed in the science classroom, how student motivation is achieved, and how the student-teacher interactions take place. The analyses made indicated that teachers' discourse in the mid-21st century in Turkey is still shaped by power dynamics. Concept teaching at the elementary school level is performed through explanations provided by the teacher, who is positioned as the center of power. This approach regards science as being unquestioned with strict boundaries filled with absolute facts. At the middle-school level, science is open to inquiry and discussion and is innovative, and entertaining. However, the disadvantages of the schools (for example, the negative discourse of other teachers) and the intense curriculum are reflected in the teachers' discourse, which prevents students from allocating more time for science and taking initiatives. However, it is the disadvantaged students in the classroom who are most negatively influenced by this situation. Yet, it is a situation that can be resolved with a change in discourse. The adoption of an intellectual perspective could also change students' perspective towards science. A stronger willingness to learn science can be effective on students' achievement in science and their intrinsic motivation. Clarifying science concept teaching by constructing definitions with students, adopting a terminological perspective, investigating argument structures in the classroom, and relating concepts to daily life can assist in creating active student participation in the classroom. The updating of the educational policies in the country is certainly going to have an impact on the direction of teacher discourse. Moreover, the exam-based educational system in Turkey leads to traditional test solving rather than to experimental approaches and focuses on knowing single correct answers, which results in no classroom discussions or recognition of the value of learning from making mistakes. This situation puts pressure on the teacher to quantitatively increase the number of students who are successful in the exam. The case in elementary schools, on the other hand, is quite different. Pedagogical requirements are needed to soften the discourse of elementary school teachers, an issue that educational policymakers should take into consideration. As a result, CDA is often used in studies that take into account social issues such as politics, ideology or racism (Sugrue, 2019; Wright \& Brookes, 2019). In the studies conducted in the field of education, it is determined that the discourses in the textbooks or other educational materials are generally examined (Babaii \& Sheikhi, 2018; Lindgren, Hildingh \& Linnér, 2017). At this point, it is possible to say that the present study is strong in terms of examining the teacher discourse in the classroom environment, but it also has a certain limitation in terms of giving a limited number of teacher discourse structures in the same study.

\section{Acknowledgements}

The author wishes to thank Dr. Kemal IZCI for thoughtful suggestions on the manuscript. Also thanks Dr. Mustafa DOĞRU, who shared his knowledge and experience with author.

\section{References}

Atkinson, J. M., \& Heritage, J. (Eds.) (1984).Structures of social action: Studies in conversation analysis. Cambridge: Cambridge University Press.

Babaii, E. \& Sheikhi, M. (2018). Traces of neoliberalism in English teaching materials: A critical discourse analysis. Critical Discourse Studies, 15(3), 247-264.

Başer, M., \& Çataloğlu, E. (2005). Effect of conceptual change oriented instruction on remediation of students' misconceptions related to heat and temperature concepts. Hacettepe University Journal of Education, 29, 4352.

Calabrese Barton, C., \& Yang, K. (2000). The culture of power and science education: Learning from Miguel. Journal of Research in Science Teaching, 37(8), 871-889.

Delpit, L. (1995). Other people's children: Cultural conflict in the classroom. New York: The New Press

Eggings, S. (1994). An introduction to systemic functional linguistics. Lender: Pinter. 
Elliott, R. (1996). Discourse analysis: Exploring action, function and conflict in social texts. Marketing Intelligence \& Planning, 14, 6, 65.

Fairclough, N. (1989). Language and power. London: Longman.

Fairclough, N. (2003). Analyzing discourse: Textual analysis for social research. London: Routledge.

Fairclough, N. \& Wodak, R. (1997).Critical discourse analysis. T.A., van Dijk (Ed.), Discourse studies: A multidisciplinary introduction (pp.258-84). London: Sage.

Fowler, R., Hodge, R., Kress, G., \& Trew, T. (1979).Language and control. London: Routledge.

Freitas, E.D. \&Palmer, A. (2016). How scientific concepts come to matter in early childhood curriculum: Rethinking the concept of force. Cultural Study of Science Education, 11,1201-1222.

Gee, P. J. (1999). An introduction to discourse analysis: Theory and method (1st ed.). London: Routledge.

Gee, P., \& Green, J. (1998). Discourse analysis, learning, and social practice: A methodological study. Review of Research in Education, 23, 119-169.

Green, T. F. (1964). A topology of the teaching concept. Studies in Philosophy and Education, 3(4), 284-319.

Guba, E., \& Lincoln, Y. (1989).Fourth generation evaluation. Beverly Hills, CA: Sage.

Hanrahan, M. U. (2005). Highlighting hybridity: A critical discourse analysis of teacher talk in science classrooms. Science Education, 90(1), 8-43.

Kress, G. (1990). Critical discourse analysis. Annual Review of Applied Linguistics, 11, 84-99.

Layng, T.V.J.(2013). Understanding concepts: Implications for science teaching. Retrieved from http:// mimio.com/ /.../whitepaper_science_teaching.ashx (25.08.2018)

Lemke, J. L. (1990). Talking science: Language, learning, and values. Norwood, NJ: Ablex.

Lindgren, E-C., Hildingh, C., \& Linnér,S. (2017). Children's stories about team selection: A discourse analysis. Leisure Studies, 36(5), 633-644.

Luke, A. (1995). Text and discourse in education: An introduction to critical discourse analysis. Review of Research in Education, 21(1), 3-48.

Moore, F.M. (2008). The role of the elementary science teacher and linguistic diversity. Journal of Elementary Science Education, 20(3), 49-61.

Rosch, E. (1999). Reclaiming concepts. In R., Núñez, \& W., Freeman (Eds.), Reclaiming Cognition: The Primacy of Action, Intention and Emotion (pp. 61-78). Thorveton, UK: Imprint.

Parker, I. (1992).Discourse dynamics: Critical analysis for social and individual psychology. London: Routledge.

Phillips, N. \& Hardy, C.(2002). Understanding discourse analysis. Thousand Oaks, CA: Sage.

Potter, J., \& Wetherell, M. (1987).Discourse and social psychology: Beyond attitudes and behavior. London: Sage.

Schill, B. \& Howell, L. (2011).Concept-based learning. Science and Children, 48 (6), 40-45.

Sugrue, E.P. (2019). A 'bad fit' for 'our' kids: politics, identity, race and power in parental discourse on educational programming \& Child well-being. Critical Discourse Studies, 16(2), 222-236.

Tezcan, H., \& Salmaz, Ç.(2005). Effects of the traditional method and constructivist approach on the understanding of atomic structure and elimination of related misconceptions. Gazi University Journal of Gazi Educational Faculty, 25(1), 41-54.

Tobias S.(1990). They are not dump, they are different: Stalking the second tier. Tucson, AZ: Research Corporations.

Olson, J.K. (2008). Concept-focused teaching. Using big ideas to guide instruction in science. Science and Children, 45-48.

Tonkiss, F. (2004).Analyzing text and speech: Content and discourse analysis. Researching Society and Culture, 2, 367-382.

van Dijk, T.A. (1997). Discourse as social interaction. London: Sage.

van Dijk, T.A. (2003). Critical discourse analysis. D. Schiffrin., D. Tannen, \& E., H. Hamilton (Ed.), In TheHandbook of discourse analysis (pp. 352-372). Oxford: Blakwell Publishing.

van Dijk, T. A. (2007). The study of discourse: An introduction. In T. A., van Dijk (Ed.), Discourse Studies (pp. 1-14). London: Sage.

von Glasersfeld, E. (1995). Radical constructivism: A way of knowing and learning. London, UK: The Falmer Press.

Vygotsky, L. S. (1987). Thinking and speech. In L.S. Vygotsky, The collected works of L.S. Vygotsky, Vol. 1, R.W. Rieber\& A.S. Carton(Eds.) Problems of general psychology (pp. 39-285), N. Minick (Trans.), New York: Plenum Press.

Weiss, G., \& Wodak, R. (2003). Introduction: Theory, interdisciplinary and critical discourse analysis. In Critical discourse analysis (pp.1-32). Palgrave Macmillan, London.

Wertsch, J., \&Toma, C. (1995). Discourse and learning in the classroom: A sociocultural approach. In L. Steffe \& J. Gale (Eds.), Constructivism in Education (pp. 159-174). Mahwah, NJ: LEA.

Wodak, R. \& Meyer, M. (2001).Methods of critical discourse analysis. London: Sage. 
Wood, L., A. \& Kroger, R., O. (2000).Doing discourse analysis: Methods for studying action in talk and text. London: Sage.

Wright, D., \& Brookes, G. (2019). 'This is England, speak English!': A corpus-assisted critical study of language ideologies in the right-leaning British press. Critical Discourse Studies, 16(1), 56-83.

\section{Author Information}

\section{Menşure ALKIŞ KÜÇÜKAYDIN}

Necmettin Erbakan University

Eregli Faculty of Education, Konya, Turkey

Contact e-mail: mensurealkis@hotmail.com 